\title{
FILOSOFIA E EDUCAÇÃO INCLUSIVA: REFLEXÕES CRÍTICAS PARA A FORMAÇÃO DOCENTE*
}

\author{
Giovani Ferreira Bezerra, \\ da Universidade Estadual de Mato Grosso do Sul \\ Doracina Aparecida de Castro Araujo, \\ da Universidade Estadual de Mato Grosso do Sul
}

Resumo: Este artigo tem por objetivo investigar pressupostos ideológicos subjacentes à proposta pedagógica de inclusão escolar, realizando, para tanto, a análise de uma reportagem publicada na Revista Nova Escola em setembro de 2003. Os dados coletados, advindos de pesquisa bibliográfica, são interpretados à luz do referencial filosófico marxista. Constata-se que a o ideário inclusivista assume uma perspectiva idealista e fetichizada, ratificando tendências escolanovistas na prática pedagógica, sem promover, todavia, uma ruptura com a sociedade capitalista. Em contrapartida, advoga-se, então, uma práxis revolucionária, favorável ao pleno desenvolvimento de pessoas com e sem deficiência, tendo-se por base as circunstâncias contraditoriamente humanizadoras, suscitadas pelo próprio movimento inclusivista. $\mathrm{O}$ artigo contribui para estudos críticos e filosóficos no campo da formação do docente e do marxismo.

Palavras-chave: Filosofia marxista. Inclusão. Práxis pedagógica. Imprensa pedagógica.

A crítica colheu nas cadeias as flores imaginárias, não para que o homem suporte as cadeias sem fantasia ou sem consolação, mas para que lance fora as cadeias e colha a flor viva.

Karl Marx, Introdução à crítica da filosofia do direito de Hegel

\footnotetext{
* Artigo recebido em 20/9/2011 e aprovado em 15/3/2012.
} 
INTRODUÇÃO

O século XXI surge perpassado pelo ideário inclusivista, forjado nas décadas anteriores, sobretudo nos anos 90 , por duas grandes declarações de alcance internacional - a Declaração mundial sobre educação para todos: satisfação das necessidades básicas de aprendizagem e a Declaração de Salamanca sobre princípios, políticas e práticas na área das necessidades educativas especiais, à qual se integra a Estrutura de ação em educação especial. A inclusão escolar de alunos com deficiência tornou-se, desde então, uma preocupação constante de governos, universidades e professores, alcançando respaldo jurídico e grande mobilização da sociedade, sem que se alterasse a base produtiva capitalista.

$\mathrm{O}$ assunto tem sido, também, um dos mais debatidos quando se pensa nos rumos da formação docente. Em que pese, porém, o fato de a escola inclusiva ser fundamental e irrenunciável para o pleno desenvolvimento dos alunos com alguma deficiência ou limitação ontogenética - superando-se o modelo segregador das classes e escolas especiais de outrora-, o movimento inclusivista tem se articulado com base em pressupostos capitalistas neoliberais. Uma análise filosófica e crítica é, portanto, necessária para compreendermos o núcleo ideológico da "pedagogia da inclusão", tal qual essa vem se concretizando nos discursos educacionais, na grande mídia, nas revistas destinadas a professores, nos manuais e bibliografias voltados à formação docente. Em nossa dissertação de mestrado, temos voltado nossa atenção para o estudo da Revista Nova Escola, dada sua influência na prática de muitos professores brasileiros, que têm nessa revista seu principal recurso bibliográfico para fundamentação teórica e atualização pedagógica. A assertiva se confirma nos dizeres de Grossi (2000, p. 4), para quem Nova Escola é "[...] revista que você [o professor] se acostumou a ler (e reler, e guardar, e pesquisar, e usar em sala de aula)".

Lançada em março de 1986, Nova Escola (doravante identificada pela sigla NE), editada pela Fundação Victor Civita, já contabiliza 25 anos de existência ininterrupta. O periódico não tem caráter científico propriamente dito, pois segue o modelo jornalístico das revistas comerciais. Entre aquelas com temática pedagógica porém, NE lidera soberana com a maior tiragem de exemplares (BARBOSA; MAZZONETTO; MIRANDA, 2007; NOVA ESCOLA, 2011). Logo, está em posição confortável na disputa ideológica pela hegemonia na formação inicial e continuada dos docentes de todo o Brasil, quando comparada a outros periódicos de mesma orientação temática. Como se lê em certo editorial da revista, $\mathrm{NE}$ "[...] sempre retratou a realidade de nossas escolas 
- e vem ajudando a moldar o futuro de nossos professores e estudantes" (GROSSI, 2011, p. 11; grifo nosso). Pesquisa realizada por Gentil (2006), com uma amostra de professores das séries iniciais do ensino fundamental, evidencia também que a revista é a mais lida pelos educadores. Assim, conhecê-la criticamente é uma exigência para quem deseja ler o discurso pedagógico além das aparências fenomênicas imediatas (KOSíK, 2002).

Já nos primórdios do século XX, o filósofo Gramsci (1995, p. 29; grifo nosso) afirmava ser "[...] interessante estudar concretamente, em um determinado país, a organização cultural que movimenta o mundo ideológico e examinar o seu funcionamento prático". Na sequência, o pensador italiano cita a escola e a igreja como as duas maiores organizações culturais de um país, sugerindo que sejam estudadas, dada sua abrangência, sem se esquecer, contudo, de mencionar a fração cultural significativa que representam: "Os jornais, as revistas e a atividade editorial [...]" (GRAMSCl, 1995, p. 29). Nesse sentido, os periódicos especializados em educação representam um excelente observatório da realidade pedagógica (OGNIER, 1984), que, assim, "[...] peut être 'photographiée dans sa richesse vivante" (OGNIER, 1984, p. 13), captada na totalidade de sua configuração ideológica.

$\mathrm{Na}$ citada pesquisa, nosso intuito tem sido mapear, explicitar e entender, com base em pressupostos marxistas, a ideologia da inclusão disseminada em NE, no período compreendido entre 2001-2011, haja vista a ampla divulgação da proposta inclusiva nos últimos anos. Neste artigo, fazemos um recorte de nossa pesquisa, apresentando a análise crítica de uma reportagem do periódico, datada de 2003 , que sintetiza os contornos ideológicos assumidos no contexto da escola inclusiva pela educação brasileira na última década. Entendemos que não se trata de negar o direito inalienável de possibilitar a todos, com ou sem deficiência, o acesso e permanência em uma escola regular; mas pensamos que a situação exige o recuo à filosofia, justamente para repensarmos o significado da ontologia humana, dos caminhos para emancipação plena do homem, visando a uma sociedade socialista.

Quando criticamos certas representações do ideário inclusivista, a intenção não é defender uma escola "excludente"; ao contrário, é combater as apropriações burguesas em torno da luta pela ampla transformação da sociedade e da escola atuais, porque essas apropriações fortalecem um discurso reformista que impede a emergência de uma práxis revolucionária, cerceando, inclusive, a plenitude dos processos pedagógicos ditos "inclusivos". É preciso, pois, compreender o fenômeno inclusão, seus reducionismo e tendências fetichizadoras, para se vislumbrarem possibilidades cada vez mais 
humanizadoras na formação e prática docentes, seja para alunos com ou sem deficiência. Consoante Kosík, acreditamos que

[...] a filosofia é uma atividade humana indispensável, visto que a essência da coisa, a estrutura da realidade, 'a coisa em si', o ser da coisa, não se manifesta direta e imediatamente. Neste sentido, a filosofia pode ser caracterizada como um esforço sistemático e crítico que visa a captar a coisa em si, a estrutura oculta da coisa, a descobrir o modo de ser do existente. (KOSíK, 2002, p. 17-18; grifo do autor)

O empenho em abordar o tema sob uma perspectiva filosófica justifica-se a fim de que possamos captar o que há de suspeito e ilusório no modo como vem sendo representada e pensada a inclusão de crianças com deficiência em nosso país, conforme objetivado, historicamente, na crônica do jornalismo educacional. Desvendar o modo de ser do existente, vale dizer, as tematizações do ideário inclusivista, com o propósito de, pelo menos, chegarmos à colocação crítica do problema, é o objetivo imediato deste trabalho. Lembrando aqui os filósofos fundadores do materialismo históricodialético, assumimos claramente nossa opção teórica, pois

essa forma de considerar as coisas parte das premissas reais e não as abandona por um instante sequer. Essas premissas são os homens, não os homens isolados e definidos de algum modo imaginário, mas envolvidos em seu processo de desenvolvimento real em determinadas condições, desenvolvimento esse empiricamente visível. (MARX; ENGELS, 2007, p. 20)

Passemos, então, à análise dos dados (coletados durante nossas leituras do periódico NE) e à sua interpretação, à luz dos pressupostos marxistas, nos limites que nos possibilita o presente texto, haja vista ser este apenas uma parte do trabalho que estamos desenvolvendo. Logo, não se tem a pretensão de esgotar o assunto, mas fomentar o debate em bases filosóficas. Ressaltamos ainda tratar-se de um resgate histórico, relativo ao ano 2003. Não obstante, os comentários tecidos a essa matéria continuam atuais ao discurso inclusivista hegemônico, em pauta nos últimos dez anos.

PONTOS E CONTRAPONTOS SOBRE A IDEOLOGIA DA INCLUSÃO NA REVISTA NOVA ESCOLA: UMA CRÍTICA MARXISTA

Em setembro de 2003, NE lança uma reportagem de capa sobre a inclusão escolar de alunos com deficiência. Intitulada $A$ inclusão que funciona, a matéria comprova a grande repercussão pedagógica que o assunto vinha assumindo. No âmbito pedagógico, NE traz proposições inclusivistas, 
centradas no lema do aprender a viver juntos, com e pela "aceitação" da diferença, essa bastante reduzida à condição resultante de uma deficiência. Nos dizeres do periódico:

Valorizar as peculiaridades de cada aluno, atender a todos na escola, incorporar a diversidade, sem nenhum tipo de distinção. Nunca o tema da inclusão de crianças deficientes esteve tão presente no dia a dia da educação - e isso é uma ótima notícia. Tal qual o caleidoscópio, que forma imagens com pedras de vários tamanhos, cores e formas, cada vez mais professores estão percebendo que as diferenças não só devem ser aceitas, mas também acolhidas como subsídio para montar (ou completar) o cenário escolar. E não se trata apenas de admitir a matrícula desses meninos e meninas - isso nada mais é do que cumprir a lei. O que realmente vale (e, felizmente, muitos estão fazendo) é oferecer serviços complementares, adotar práticas criativas na sala de aula, adaptar o projeto pedagógico, rever posturas e construir uma nova filosofia educativa. (GUIMARÃES, 2003, p. 43; grifos nossos)

De fato, era - e continua a ser - um enorme avanço defender a abertura das escolas regulares para alunos com deficiência ou outras singularidades, apesar de não se dispensar, pela simples enunciação da concordância, a análise concreta do fenômeno. Do fragmento acima, é imprescindível realizar determinadas observações. A primeira delas é formular uma crítica ao fetichismo da diferença ou da diversidade. Não se ignora que o professor precise conhecer o curso específico do desenvolvimento de seus alunos, isso é, identificar singularidades, limitações e habilidades. Assim, pode intervir nesse processo, com o fito de dar-lhe uma direção consciente, não espontânea, capaz de vencer as resistências impostas pelos eventuais comprometimentos ontogenéticos. Consoante Vygotski (1997, 17; grifo do autor), "[...] para el pedagogo es importante conocer la peculiaridad del camino por el cual debe conducir al niño. La clave de la peculiaridad la brinda la ley de transformación del menos del defecto en el más de la compensación".

A percepção da singulidade não é, porém, um fim em si mesma; é sempre um meio para o professor repensar suas estratégias de ensino no sentido de levar todos, mesmo por vias distintas, à plenitude, ou ao mais próximo possível da condição humana, do homem como ser social e histórico, não apenas biológico (VYGOTSKI, 1997, 2004). O mesmo autor lembra que, não obstante as exigências peculiares reclamadas à pedagogia, perante casos de deficiência, "[...] no debemos olvidar que es preciso educar no a un ciego, sino ante todo a un niño" (VYGOTSKI, 1997, p. 81; grifo do autor). Da leitura de sua obra, depreende-se que é fundamental não perder de vista a pessoa a quem se educa, a dialética entre particularidade e genericidade. Percebemos, 
contudo, que NE, inserida no universo pós-moderno e neoliberal, oblitera essas relações (quando autonomiza e mistifica a diferença, a diversidade) a ponto de retratá-las como categorias abstratas. Nesse sentido, ambas tornam-se um fetiche, ganham vida fora dos homens que as encarnam, como propriedade viva e pulsante de sua singularidade.

É oportuno explicitar o conceito de fetichismo aqui utilizado, porquanto o fazemos com base no uso marxiano do termo. O filósofo de OCapital (1996) se propõe a explicar o segredo da mercadoria, seu caráter enigmático na sociedade capitalista, e chega à conclusão de que o mistério não decorre nem do valor de uso, nem da grandeza responsável pela determinação do valor, ou seja, da quantidade de trabalho humano dispendida em certo intervalo de tempo. Para Marx,

o misterioso da forma mercadoria consiste, portanto, simplesmente no fato de que ela reflete aos homens as características sociais do seu próprio trabalho como características objetivas dos próprios produtos de trabalho, como propriedades naturais sociais dessas coisas e, por isso, também reflete a relação social dos produtores com o trabalho total como uma relação social existente fora deles, entre objetos. [...]. Não é mais nada que determinada relação social entre os próprios homens que para eles aqui assume $a$ forma fantasmagórica de uma relação entre coisas. Por isso, para encontrar uma analogia, temos de nos deslocar à região nebulosa do mundo da religião. Aqui, os produtos do cérebro humano parecem dotados de vida própria, figuras autônomas, que mantêm relações entre si e com os homens. Assim, no mundo das mercadorias, acontece com os produtos da mão humana. Isso eu chamo o fetichismo que adere aos produtos de trabalho, tão logo são produzidos como mercadorias, e que, por isso, é inseparável da produção de mercadorias. (MARX, 1996, p. 198-199; grifo nosso)

Destarte, a fetichização ocorre aos homens porque, no estranho mundo das mercadorias, eles passam a se relacionar com os produtos de seu trabalho, tanto material como intelectual, como se esses fossem criações independentes do processo produtivo, em vez de atividade humana historicamente situada. Aquilo que é produzido pela mão humana ganha autonomia e põe-se a regular as relações intra e interpessoais, convertendoas em uma relação entre coisas (reificação), as quais fogem ao controle dos indivíduos. Os objetos, conquanto sejam entendidos como mercadorias, assumem superioridade sobre o produtor, nega-o e parece ter sempre existido dessa maneira, pois é naturalizado. No caso da inclusão escolar, pensamos que fenômeno semelhante venha ocorrendo nas últimas décadas, evidentemente não com a mesma intensidade, tampouco de modo econômico stricto sensu. 
O tom fetichista da pedagogia inclusiva surge em trechos emblemáticos, tais como "[...] incorporar a diversidade [...]","....] cada vez mais professores estão percebendo que as diferenças não só devem ser aceitas, mas também acolhidas como subsídio para montar (ou completar) o cenário escolar" (GUIMARÃES, 2003, p. 43; grifos nossos); reestruturar o sistema de ensino "[...] com o objetivo de fazer com que a escola se torne aberta às diferenças [...]" (DUTRA apud GUIMARÃES, 2003, p. 46; grifo nosso). Os fragmentos mostram que o homem, como indivíduo singular e genérico, está subsumido pela sua "diferença", pela abstração metafísica sob a qual se erige o conceito de diversidade. Não é a pessoa que se "incorpora" ao dia a dia escolar, não é o aluno que deve ser "acolhido", mas a "diferença", o "diverso", a "parte" e o "fragmento". Em vez de uma relação entre homens, sujeitos da práxis, a escola inclusiva, como retratada em NE, preconiza uma relação abstrata entre e com as diferenças, que se autonomizam, ganham vida própria, como espectros, sem corpo e substância concretos, direcionando o sentido dos relacionamentos escolares.

Em um segundo nível de leitura, a revista apresenta ecos do discurso benevolente. A "diferença" seria uma exterioridade a qual se deve aceitar, acolher e, com certo esforço, valorizar. Sua presença na escola "regular" é (quase) uma concessão. Para "lidar" com essa diferença surge a necessidade de adotar práticas criativas na sala de aula, adaptar o projeto pedagógico, rever posturas e construir uma nova filosofia educativa" (GUIMARÃES, 2003, p. 43). Implicitamente, com apelos escolanovistas, responsabiliza-se o professor pelo sucesso da inclusão, como prática restrita ao microcosmo da sala de aula: "O que realmente vale [...] é [...] adotar práticas criativas na sala de aula [...]" (p. 43; grifo nosso). Além disso, basta "[...] adaptar o projeto pedagógico [...]" (p. 43), provavelmente inserindo objetivos "inclusivos" ao modelo de escola já existente, como algo a mais, "encaixado". Está aí o reflexo típico do ideário inclusivista, que é uma artimanha capitalista - ou, em linguagem marxiana (1996, p. 197), uma manha teológica, uma sutileza metafísica - para manter o "organismo" social adaptado, equilibrado às novas demandas (justas) por direitos iguais, ao passo que se mantém a sociedade de classes.

Na mesma direção ideológica, a escola inclusiva se constrói pela mudança individual de comportamentos; depende da revisão particular de posturas e atitudes. É um desafio para o indivíduo e para as escolas empreendedoras que, a despeito de quaisquer dificuldades, tentam efetivar a nova proposta com determinação incansável. Nem todos aceitariam tal desafio, apesar de gestos inclusivos (ou melhor, acolhedores) serem entendidos como um ato recompensador, apto a promover verdadeiras mudanças internas no cenário escolar, quase uma "microrrevolução": "Quem 
enfrenta o desafio garante: quando a escola muda de verdade, melhora muito, pois passa a acolher melhor todos os estudantes (até os considerados 'normais')"'(GUIMARÃES, 2003, p. 44). Logo, aqueles que se recusam a participar da mudança estariam deixando de "lucrar" com esses benefícios.

A revista Nova Escola tenta evitar os impasses suscitados perante a implantação do projeto inclusivista, que é apresentado, unicamente, pelo ângulo positivo de "quem aceita o desafio". Somente esses estariam autorizados a comentar o assunto. Só valem as experiências de sucesso, os relatos de vitória, pois eles evocam a aparência de harmonia, sugerem que é possível driblar o preconceito; anulam toda a conflitividade social e ideológica que perpassa a escola. Afinal, o problema não está em revolucionar a sociedade, em colocar todos os meios materiais e intelectuais a serviço da humanização plena de cada homem, cada povo, segundo enfatiza Leontiev (1978). Desse modo, a matéria de NE põe no mundo ideal a força material necessária à transformação escolar, defendendo, em si mesma, a tarefa de "[...] construir uma nova filosofia educativa" (GUIMARÃES, 2003, p. 43). Sem dúvida, a proposição de uma nova filosofia educativa é passo importante para revolucionar as relações pedagógicas e sociais travadas no interior da escola, porque existe o movimento reverso da superestrutura à base.

Mas essa "filosofia" não deixa de ser, perante a lógica do capital, ambígua e, sobretudo, vazia de significado práxico, se não é contextualizada nem reconhecida em seus limites. Além do mais, é sempre preciso indagar quem propõe essa filosofia e qual é seu núcleo teórico-epistemológico, sistematizando-o conscientemente (GRAMSCl, 1995). Do contrário, pode-se cair no contraste entre "[...] duas concepções de mundo, uma afirmada por palavras e outra manifestando-se na ação afetiva, [que] nem sempre se deve à má-fé" (GRAMSCI, 1995, p. 14). Dito de outro modo, a simples mudança no discurso filosófico, sem a perspectiva de revolução conjunta nas relações capitalistas de produção, estabelecidas na infraestrutura, acaba redundando no paradoxo de se incluir, satisfatoriamente, apenas no plano das ideias; na prática concreta, a exclusão tende a permanecer, embora, na aparência, possa diminuir.

Há que se mencionar ainda mais sobre o aspecto idealista de tal "filosofia", cujas formulações não ultrapassam o âmbito da escola e dos agentes educacionais. Segundo anunciava o subtítulo da reportagem em estudo, "Mais do que criar condições para os deficientes (sic), a inclusão é um desafio que implica mudar a escola como um todo, no projeto pedagógico, na postura diante dos alunos, na filosofia..." (GUIMARÃES, 2003, p. 43; grifo nosso). $\mathrm{Na}$ realidade, a dialética inclusão $x$ exclusão precede a dinâmica escolar e aí 
se reflete; é, antes, um problema sociológico mais amplo a ser compreendido em sua totalidade, da qual as relações intraescolares participam como uma das manifestações possíveis do fenômeno. Condicionar a proposta inclusiva a modificações burocráticas, didático-pedagógicas ou meramente atitudinais é tratar o assunto com superficialidade e encobrir seus nexos causais; é tergiversar sobre a existência objetiva da sociedade excludente, o que mais dificulta o enfrentamento dessa, em vez de mediar sua desejada superação, conforme também almejaria o próprio discurso inclusivista.

Mas é exatamente circunscrita a tais condicionamentos que NE explica a mudança a ser processada rumo à escola inclusiva, recorrendo a argumentos de autoridade para embasar sua posição ideológica. Conforme dispõe o texto de Guimarães (2003, p. 44; grifo nosso),

Essa mudança é simples? É claro que não. Na verdade, ainda é difícil encontrar professores que afirmem estar preparados para receber em classe um estudante deficiente. A inclusão é um processo cheio de imprevistos, sem fórmulas prontas e que exige aperfeiçoamento constante. "Do ponto de vista burocrático, cabe ao corpo diretivo buscar orientação e suporte das associações de assistência e das autoridades médicas e educacionais sempre que a matrícula de um aluno deficiente é solicitada", explica Cláudia Dutra, secretária de Educação Especial da Educação.

“Do ponto de vista pedagógico, a construção desse modelo [inclusivo] implica transformar a escola, no que diz respeito ao currículo, à avaliação e, principalmente, às atitudes", complementa Maria Teresa [Eglér] Mantoan, coordenadora do Laboratório de Estudos e Pesquisas em Ensino e Diversidade da Universidade de Campinas.

De início, o excerto comprova que o periódico reconhece algumas dificuldades na efetivação da proposta de inclusão escolar, pois essa é retratada como um processo complexo, possivelmente dificultado pela insuficiência da formação docente e pela imprevisibilidade do comportamento humano. Para driblar os "imprevistos", haveria, ao professor, a exigência de um "aperfeiçoamento constante", apesar de não se explicitar como isso ocorreria, nem sobre quais bases epistemológicas. Em seguida, a inclusão aparece condicionada a dois polos: o burocrático e o pedagógico. $\mathrm{O}$ primeiro responsabiliza o corpo diretivo de cada escola pela busca de apoios e infraestrutura reclamados para garantir o êxito dessa proposta; o segundo vê, na transformação interna da escola e de sua dinâmica curricular, o pressuposto básico para a construção do modelo inclusivo, defendendo que as atitudes dos atores pedagógicos seriam o ponto principal a ser "transformado". 
Também aqui - não obstante o risco da tautologia - o ideário inclusivista sustenta uma tese ingênua, porque tem na transformação da escola e dos indivíduos a referência precípua que norteia sua discursividade; não considera, portanto, as mediações sociais mais amplas. O universo escolar vale em si e por si; está isento de maiores conflitos sociais e caminha na direção do equilíbrio, da harmonia interna, conquanto se (trans)formem atitudes, ações e disposições individuais, objetivadas em uma nova didática. Os homens teriam a prerrogativa de alterar sua subjetividade com absoluta determinação, pois isso dependeria apenas de sua vontade pessoal. Em última instância, poderia abstrair-se por inteiro da sociedade em que vive, alterando, tão logo deseje, suas atitudes e valores, apesar de se manter inquestionável a sociedade burguesa. A consciência estaria isenta de quaisquer influências significativas da realidade circundante, não obstante estar marcada pelas diversas formas de alienação social, econômica e psíquica. Entre incluir e excluir existiria meramente interposição de uma escolha filosófica, de acordo com a vontade de cada um.

Na perspectiva de Marxe Engels (2007), isso significa descambar para o idealismo, visto que a consciência dos indivíduos não é constituída com base em ideias deslocadas da materialidade concreta. Ambos combatiam os jovens hegelianos, que davam autonomia às representações ideológicas e acreditavam que a libertação do homem se desse simplesmente no plano ideal, pela "troca" de certas ideias por outras, de uma consciência velha por uma nova, sem maiores ponderações quanto aos determinantes sóciohistóricos e econômicos; ou, nas palavras dos autores: "Nenhum desses filósofos teve a ideia de se perguntar qual era a ligação entre a filosofia alemã e a realidade alemã, a ligação entre a sua crítica e o seu próprio meio material" (MARX; ENGELS, 2007, p. 10). Na contemporaneidade, situação análoga parece reeditar-se com a suposta "filosofia" inclusiva.

Todavia, mediante essa crítica, não é nossa intenção retirar do indivíduo as responsabilidades pela sua vida, a possibilidade de conduzila, nem colocá-lo como figura passiva; ou como ente despersonalizado, subjugado pelas circunstâncias externas, sem a mínima autonomia em face delas, à semelhança de uma marionete nas mãos do "sistema". Pensar assim é também ser partidário do imobilismo que alimenta pensamentos como este: haja vista a existência de condições desfavoráveis, toda tentativa de alterar o status quo dominante revela-se estéril. Para a deflagração de atitudes e práticas revolucionárias, ficar-se-ia placidamente à espera de transformações radicais espontâneas, advindas com agravamento das contradições internas desse sistema, as quais redundariam em um colapso social generalizado, 
favorável à revolução. Se as circunstâncias fazem os homens e sua consciência, também os homens fazem e transformam as circunstâncias, porque essas não são imposições determinadas pela natureza, mas criações sócio-históricas da humanidade (MARX; ENGELS, 2007).

Dito de outro modo, tentamos aqui evidenciar que a transformação da sociedade, da escola, das ações humanas enfim, não acontece apenas pela via discursiva, sem levar em conta o processo de vida dos homens históricos reais (MARX; ENGELS, 2007), ao contrário do que supõe o ideário inclusivista, conforme exemplificado em NE e no discurso atual. Os filósofos supracitados combatiam o idealismo, aparentemente emancipador, da escola jovem-hegeliana, afirmando que seus ideólogos lutavam contra ilusões da consciência.

Como, em sua imaginação, as relações dos homens, todos os seus atos e gestos, suas cadeias e seus limites são produtos da sua consciência, coerentes consigo próprios, os jovens hegelianos propõem aos homens este postulado moral: trocar a sua consciência atual pela consciência humana, crítica ou egoísta e, assim fazendo, abolir seus limites. Exigir assim a transformação da consciência equivale a interpretar de modo diferente o que existe, isto é, reconhecê-lo por meio de uma outra interpretação. (MARX; ENGELS, 2007, p. 9; grifo nosso)

A proposta inclusivista entende a problemática educacional de forma parecida, ao propor a mudança do modelo excludente e segregador pelo modelo inclusivo. $O$ alicerce que sustentava o antigo modelo não é alterado, apenas reinterpretado, o que significa não revolucionar a sociedade e sua base material e, sim, conservá-la, projetando para o ser individual toda a determinação histórica pela mudança. Gramsci (1995) também formula reflexões a esse respeito, como convém retomar. $O$ pensador italiano defendia a formação política do homem, como forma de proporcionar-lhe o domínio consciente e volitivo de sua personalidade, de maneira que o indivíduo, transformado em um intelectual dirigente, pudesse exercer a crítica-ação na realidade histórica vivida. Não obstante, é muito claro sobre os limites da transformação isolada em cada pessoa, sobretudo quando se deixa de lado o conceito de gênero humano e o conjunto das atividades sociais transformadoras; não restritas, portanto, ao universo escolar imediato. Consoante suas palavras,

o homem deve ser concebido como um bloco histórico de elementos puramente subjetivos e individuais e de elementos de massa - objetivos ou materiais - com os quais o indivíduo está em relação ativa. Transformar o mundo exterior, as relações gerais, significa fortalecer a si mesmo, desen- 
volver a si mesmo. É uma ilusão, e um erro, supor que o 'melhoramento' ético seja puramente individual: a síntese dos elementos constitutivos da individualidade é 'individual', mas ela não se realiza e desenvolve sem uma atividade para o exterior, atividade transformadora das relações externas, desde as com a natureza e com os outros homens - em vários níveis, nos diversos círculos em que se vive - até a relação máxima que abraça todo o gênero humano. (GRAMSCl, 1995, p. 47-48; grifo nosso)

Na reportagem considerada, a revista insiste, porém, em depositar no professor - visto independentemente das demais condições históricas, de formação e trabalho - a exclusividade pelo bom ou mau "funcionamento" da inclusão de pessoas com deficiência, a responsabilidade direta pelo seu "melhoramento" docente. O relato seguinte ilustra com clarividência os comentários e reforça a tese de que o periódico sustenta a concepção de individualismo neoliberal. Em certo trecho da matéria, lê-se:

Era rotina. Durante as aulas, enquanto a professora Marta Seibert explicava os conteúdos, Shaiane Esdral, 16 anos, levantava-se da carteira e saía em direção ao pátio. “Tchau”, dizia a menina, sorrindo. Todos pensavam que era uma manifestação atípica causada pela síndrome de down. E lá iam professores e coordenadores tentar resgatar a jovem. "Foi então que eu percebi. $O$ problema não estava nela, mas no nosso jeito de dar aula", afirma a professora da $4^{\mathrm{a}}$ série da Escola Municipal Dora Abreu, em Cachoeira do Sul, a 200 quilômetros de Porto Alegre. O ensino não fazia sentido para a classe. Sua didática era mecânica e não cativava. "Só que a maioria, por comodidade, fingia que estava tudo bem". (GUIMARÃRES, 2003, p. 46; grifos nossos)

Não desconsideramos que o professor deva rever sua práxis para proporcionar a todos os alunos condições de aprendizagem, não apenas de ensino, superando-se a versão escolar da absoluta passividade do aluno que, nesse cenário, está alienado dos conteúdos, distante do sentido humanizador que esses possam conferir à sua personalidade. A inclusão escolar de pessoas com deficiência repõe constantemente o desafio de empreender esse redirecionamento pedagógico, mas isso não precisa se traduzir em uma culpabilização do educador, muito menos na busca de didáticas que "cativem". Ao citar, no relato acima, termos como didática mecânica, que não cativava, não fazia sentido, pode-se, implicitamente, notar a oposição ideológica entre escola tradicional e escola nova ou, para ser mais exato, neoescolanovismo. Os escolanovistas e neoescolanovistas tendem a supervalorizar a emoção na sala de aula, a motivação dos alunos, a intersubjetividade, relegando a plano secundário a transmissão-assimilação dos conteúdos (SAVIANI, 2009, 2010). 
Levado às últimas consequências, esse discurso em defesa por uma escola "cativante" acaba provocando o esvaziamento pedagógico, ao transformar aulas em shows, em espetáculos que seduzem e cativam, mas pouco ensinam. Semelhante tendência é reforçada pelo ideário inclusivista hodierno, o qual incorpora e revigora pressupostos do movimento escolanovista, como se nota pelos procedimentos pedagógicos que (de acordo com a reportagem visada) seriam adotados em uma determinada escola, com o intuito de garantir a"inclusão que funciona".Tais procedimentos envolveriam:

- Trabalho em grupo e atividades diversificadas que possam ter diversos níveis de compreensão e desempenho.

- Predomínio da experimentação, da criação, da descoberta e da co-autoria do conhecimento.

- Elaboração de debates, pesquisas e registros escritos.

- Avaliação do desenvolvimento da turma do ponto de vista da evolução das competências. (GUIMARÃES, 2003, p. 47; grifos nossos)

Gostaríamos de chamar a atenção para alguns aspectos subjacentes a essas proposições, pois acreditamos que estejam, intencionalmente ou não, ratificando o neoescolanovismo e, consequentemente, a ordem liberalburguesa, em detrimento de uma perspectiva revolucionária na e da escola. Observa-se que os três primeiros itens reúnem basicamente características dos métodos novos. Segundo Piaget (apud DUARTE, 2001, p. 277; grifos nossos), "Os novos métodos, os métodos da atividade, insistem [...] na relação das crianças entre si. Otrabalho em grupos, a pesquisa conjunta, o self government etc. implicam na cooperação em todos os domínios intelectuais e morais". Saviani (2009) também indica que os métodos didáticos escolanovistas pautam-se pelos projetos de pesquisa e pelo trabalho docente com pequenos grupos de alunos, com ênfase na livre iniciativa discente. Nessa perspectiva, os estudantes precisam experimentar para "criar"e "descobrir" os conteúdos, individualmente e/ou em "colaboração".

Logo, no trecho de NE, anteriormente reproduzido, a concepção predominante é a do aprender a aprender e do aprender a viver juntos. Não há como dizer o oposto, em especial quando se lê a segunda proposição "didática": "Predomínio da experimentação, da criação, da descoberta e da co-autoria do conhecimento" (GUIMARÃES, 2003, p. 47). Uma observação a ser feita é sobre a incorporação da pedagogia das competências ao ideário neoescolanovista, construtivista, ou, pelo menos, do seu jargão peculiar no discurso pedagógico. $\mathrm{O}$ último tópico cita que a escola inclusiva retratada 
na reportagem de NE utiliza-se como "procedimento" a "Avaliação do desenvolvimento da turma do ponto de vista da evolução das competências (p. 47). A pedagogia das competências, conforme aponta Duarte (2010, p. 42; grifo nosso), distingue-se pela "[...] tentativa de decomposição do aprender a aprender em uma listagem de habilidades e competências cuja formação deve ser objeto da avaliação, em lugar da avaliação da aprendizagem de conteúdos". Tal abordagem legitima a sociedade competitiva do mercado globalizado e a forja à sensação de constante inadaptação de alunos e professores em um mundo mutante, calcado em valores e comportamentos pragmáticos.

O pragmatismo, aliás, é uma faceta bem visível na matéria de NE que está sendo analisada neste item. A revista traz uma listagem de dicas e orientações "úteis" aos professores, relacionadas aos "cuidados diferentes para cada deficiência" (GUIMARÃES, 2003, p. 44). As sugestões disponibilizadas pelo periódico não se apoiam, diretamente, em fontes bibliográficas especializadas, mas, como informado, “[...] mesclam informações do Kit Escola Viva, criado pelo MEC em conjunto com a associação Sorri Brasil, com indicações elaboradas pela Procuradoria Federal dos Direitos do Cidadão" (GUIMARÃES, 2003, p. 44). Entendemos que, em 2003, quando a proposta inclusiva era muito recente, muitas dessas dicas foram (e não deixam de sê-lo ainda hoje) importantes para o professor rever sua práxis, com a adoção de práticas favoráveis à presença de alunos com deficiência nas salas de aula regulares, ajudando-o a promover, em alguns casos, adequações relativamente simples, mas fundamentais, para propiciar a todos a aprendizagem.

Nesse ponto, é possível dizer que a revista contribui para dirimir algumas dúvidas práticas sobre o trabalho docente em um cenário inclusivo, ao apontar possibilidades de ação aos docentes, mormente na época de publicação da matéria, quando pairavam grandes dúvidas sobre o assunto, mesmo em questões elementares. Havia, pois, uma carência objetiva na formação docente. Dado seu poder de difusão nas escolas de todo o país, na qualidade de periódico educacional mais lido pelos docentes da educação básica, segundo já explicitado na Introdução, NE supria, em parte, o anseio repentino por informações quanto à escola inclusiva e as formas de se concretizá-la. Entretanto, em última análise, as dicas descambam para o utilitarismo pragmático, lembram um pequeno receituário; projetam para o professor a responsabilidade direta pela emergência da "inclusão que funciona", como revela o uso de verbos no imperativo: "consiga", "pergunte", "use", "garanta", "busque", "informe-se", dentre outros exemplos (GUIMARÃES, 2003, p. 44-45).

Nesses termos, a revista coloca-se, por assim dizer, como instância discursiva privilegiada, que detém o conhecimento a ser repassado ao 
professor. NE direciona como deve ser sua prática, como ele deve fazer e agir em sala de aula, sem fomentar o diálogo científico, o confronto teórico, o entendimento menos apressado acerca das deficiências e o estudo crítico-filosófico sobre as práticas e proposições inclusivas. Prevalece, pois, o imediatismo que aliena o professor de sua própria práxis e o deixa estranhado de seu trabalho.

\section{CONSIDERAÇÕES FINAIS}

Ainda hoje, a inclusão escolar de alunos com deficiência insere-se como tema recorrente na pauta educacional. Nota-se, pois, a emergência de uma nova sensibilidade pedagógica que pretende fazer da escola inclusiva uma grande realização ético-política e ideológica, apesar de isso ainda ocorrer em sentido idealizado, mediante o culto fetichista da aparência fenomenológica dos fatos, em detrimento do estudo crítico acerca das relações essenciais que o motivam (MARX, 2011). Em nome do pragmatismo, negligencia-se a atitude filosófica perante a realidade e coloca-se no professor, visto como ser abstrato, toda a responsabilidade pelo êxito ou fracasso da inclusão escolar. No Brasil, acompanhando as tendências mundiais, o paradigma inclusivo permanece em processo de consolidação, porquanto bastante contraditório, já que se torna cada vez mais suspeito falar de inclusão sob a égide de uma sociedade capitalista. Por conseguinte, há a necessidade de se refletir mais detida e dialeticamente sobre os pressupostos políticos, educacionais e filosóficos que subjazem à proposta da escola inclusiva, conforme essa foi emergindo em nosso país.

Na direção do exposto, a análise da temática em revistas pedagógicas revela-se uma opção metodológica estratégica, já que possibilita compreender como a inclusão escolar de pessoas com deficiência tem sido ideologicamente tematizada e representada ao longo dos últimos anos, quando as discussões em torno do assunto tornaram-se mais evidentes. Mediante a pesquisa em publicações da imprensa especializada em educação, a perspectiva inclusivista pode ser mapeada em seus contornos ideológicos, subsidiando-se a formação crítica do docente no âmago do modelo econômico vigente. $O$ fato, assim entendido, não dispensa a luta diuturna para se propiciar a todos os alunos - o que significa inclusive não negligenciar a singularidade ontogenética daqueles que tenham alguma deficiência - mediações pedagógicas para aproximá-los do universo cultural o mais amplo e enriquecedor possível; tampouco nos isenta de considerar as implicações disso para a prática concreta dos professores. Com a análise, precisamos pensar também no fortalecimento da formação teórico-prática do professor, 
tanto inicial como continuada, para tornar sua ação realmente democrática, consciente e eficaz, sobretudo perante a inclusão de alunos com deficiência. $E$ isso vai além de simples dicas.

Sabemos, contudo, que a crítica pela crítica é vazia. Conforme assevera Marx (2008, p. 8; grifos do autor), "A crítica já não é fim em si, mas apenas um meio; a indignação é o seu pathos essencial, e a denúncia a sua principal tarefa". Em outras palavras, o estudo histórico e filosófico, pela leitura da mídia impressa, com o fim de denunciar os pressupostos (neo) liberais do ideário inclusivista, como defendemos, só tem sentido se for um meio para a proposição de uma nova forma de organização social e escolar, comprometida com a totalidade do gênero humano; se estiver vinculado a um objetivo maior de emancipação coletiva das condições capitalistas hoje vigorantes, qual seja: o de planejar e construir "[...] um sistema de educação que lhes assegure [a todos os homens, indistintamente] um desenvolvimento multilateral e harmonioso que dê a cada um a possibilidade de participar enquanto criador em todas as manifestações de vida humana" (LEONTIEV, 1978, p. 284).

Na direção considerada, deve-se esclarecer também que, a despeito de apresentar-se de forma "ilusória", como nova panaceia, a inclusão escolar encerra uma dimensão paradoxalmente revolucionária, no sentido de questionar a organização da escola e da sociedade vigentes. Como afirma Mantoan (2006, p. 196), “[...] a inclusão questiona não somente as políticas e a organização da educação especial e regular, como também o próprio conceito de integração". Em outras palavras, a perspectiva da inclusão escolar, embora vinculada a pressupostos ideológicos que seguem justificando a sociedade de classes, abre também um espaço contraditório e tensivo para se repensar os limites e possibilidades da educação brasileira nos últimos decênios. Isso porque não deixa de proporcionar certa visibilidade e participação social aos sujeitos com deficiência, bem como a tantos outros, historicamente preteridos pela lógica capitalista.

Com isso, vislumbra-se a emergência de práticas educacionais e sociais mais humanizadoras. Essas práticas precisam ser cada vez mais socializadas e ampliadas para toda a população, como parte de um projeto revolucionário e contra-hegemônico, que fomente o embate ao modelo social excludente em voga. Tal é a dimensão da tarefa revolucionária que, em termos contraditórios, deduz-se a partir do próprio movimento inclusivista; não obstante ser este marcado pelo caráter idealista, fetichizado e não crítico, como descrito ao longo do texto, haja vista sua proposição dar-se sob a égide do modo capitalista de produção. Nesse sentido, pensamos que, 
sendo as ilusões e suas cadeias "floridas" duramente combatidas, por meio de um esforço teórico para a interpretação crítica e desmistificada acerca da ideologia "inclusiva", começam-se a delinear condições objetivas para que desabroche a flor viva, isso é, a práxis revolucionária.

\section{PHILOSOPHY AND INCLUSIVE EDUCATION: CRITICAL REFLECTIONS ON TEACHER} FORMATION

ABSTRACT: This article sets out to investigate the ideological assumptions underlying the pedagogical proposal of inclusive education, and does so by analyzing an article published in the Nova Escola journal in September 2003. The data collected from a review of the literature was interpreted in the light of standard Marxist philosophy. It was seen that the inclusive ideal takes on an idealistic and fetishized perspective, which confirms the Escola Nova trends in educational practice, without however, breaking with capitalist society. So in compensation a revolutionary practice is defended, conducive to the full development of people with or without disabilities, using the contradictorily humanizing characteristics brought about by the inclusive movement itself as a basis. The paper contributes to critical and philosophical studies in the field of teacher formation and Marxism.

KeY WORDS: Marxist philosophy. Inclusion. Pedagogical práxis. Pedagogical press.

\section{REFERÊNCIAS}

BARBOSA, A. J. G.; MAZZONETTO, K.; MIRANDA, J. A. Inclusão escolar na revista Nova Escola. In: CONGRESSO BRASILEIRO MULTIDISCIPLINAR DE EDUCAÇÃO ESPECIAL, 4, 2007, Londrina. Disponível em: http://www.psiquiatriainfantil.com.br/congressos/ uel2007/057.htm. Acesso em: 8 out. 2011.

DUARTE, N. O debate contemporâneo das teorias pedagógicas. In: MARTINS, L. M.; DUARTE, N. (Orgs.). Formação de professores: limites contemporâneos e alternativas necessárias. São Paulo: Cultura Acadêmica, 2010. p. 33-49. Disponível em: http://www. culturaacademica.com.br/download-livro.asp?ctl_id=113. Acesso em: 21 dez. 2011.

DUARTE, N. Vygotski e o "aprender a aprender": crítica às apropriações neoliberais e pós-modernas da teoria vigotskiana. 2. ed. rev. e ampl. Campinas: Autores Associados, 2001.

GENTIL, M. S. Revistas da área da educação e professores - interlocuções. 160f. Tese (Doutorado em Educação) - Faculdade de Educação, Universidade Estadual de Campinas, Campinas, 2006. Disponível em: http://www.bibliotecadigital.unicamp.br/ document/?code=vtls000378392\&fd=y. Acesso em: 9 out. 2011.

GRAMSCI, A. Concepção dialética da história. Trad. Carlos Nelson Coutinho. 10. ed. Rio de Janeiro: Civilização Brasileira, 1995. 
GROSSI, G. P. Obrigado, professor. Nova Escola: a revista de quem educa, São Paulo, ano xxvi, n. 239, p. 10-11, jan.-fev. 2011. (Edição Comemorativa de 25 anos).

GUIMARÃES, A. A inclusão que funciona. Nova Escola: a revista do professor, São Paulo, ano xviii, n. 165, p. 42-47, set. 2003.

KOSÍK, K. Dialética do concreto. Trad. Célia Neves e Alderico Toríbio. 7. ed. Rio de Janeiro: Paz e Terra, 2002.

LEONTIEV, A. N. O desenvolvimento do psiquismo. Trad. Manuel Dias Duarte. Lisboa: Livros Horizonte, 1978.

MANTOAN, M. T. E. O direito de ser, sendo diferente, na escola. In: RODRIGUES, D. (Org.). Inclusão e educação: doze olhares sobre a educação inclusiva. São Paulo: Summus, 2006. p. 183-209.

MARX, K. Os economistas. In: O capital: crítica da economia política. Livro l: o processo de produção do capital. Trad. Regis Barbosa e Flávio R. Kothe. São Paulo: Nova Cultural, 1996. v. I. ( Prefácios e capítulos de I a XII).

MARX, K. Para a crítica da filosofia do Direito de Hegel: Introdução. Trad. de Artur Morão. Covilhã: LusoSofia, 2008. Disponível em: http://www.lusosofia.net/textos/marx_karl_ para_a_critica_da_filosofia_do_direito_de_hegel.pdf. Acesso em: 20 dez. 2011.

MARX, K. Transformação do valor ou do preço da força de trabalho em salário. In: $O$ capital: crítica da economia política. Livro I. Trad. Reginaldo Sant' Anna. 24 ed. Rio de Janeiro: Civilização Brasileira, 2011. p. 614-622. v. II.

MARX, K.; ENGELS, F. A ideologia alemã. Trad. Luis Cláudio de Castro e Costa. 3. ed. São Paulo: Martins Fontes, 2007.

NOVA ESCOLA: a revista de quem educa. São Paulo: Abril/ Fundação Victor Civita, ano xxvi, n. 239, jan./fev. 2011. (Edição Comemorativa de 25 anos).

OGNIER, P. L'idéologie des fondateurs et des administrateurs de l'école républicaine à travers la "Revue Pédagogique" de 1878 à 1900. Revue Française de Pedagogie, [S.I], v. 66, n. 66, jan./fév./mars. 1984. p. 7-14. Disponível em: http://www.persee.fr/web/revues/ home/prescript/article/rfp_0556-7807_1984_num_66_1_1577. Acesso em:4 jan. 2012. SAVIANI, D. Escola e democracia. 41. ed. rev. Campinas: Autores Associados: 2009.

SAVIANI, D. Histórias das ideias pedagógicas no Brasil. 3. ed. rev. Campinas: Autores Associados, 2010.

VYGOTSKI, L. S. Obras escogidas: fundamentos de defectología. Trad. Julio Guillermo Blank. Madrid: Visor, 1997. Tomo V.

VYGOTSKI, L. S. A transformação socialista do homem. Trad. Nilson Dória. [S.I.]: Marxists Internet Archive, 2004. Disponível em: http://www.marxists.org/portugues/ vygotsky/1930/mes/transformacao.htm. Acesso em: 6 set. 2009. 
GIOVANI FERREIRA BEZERRA é mestrando pelo Programa de PósGraduação em Educação da Universidade Estadual de Mato Grosso do Sul (Ulems), Unidade Universitária de Paranaíba, com bolsa da Capes. E-mail: sio_bezerra@hotmail.com

DORACINA APARECIDA DE CASTRO ARAUJO, doutora em Educação pela Universidade Estadual de Campinas (Unicamp), é professora da Universidade Estadual de Mato Grosso do Sul (Ulems). É docente do curso de Pedagogia e docente e coordenadora do Programa de Pós-Graduação em Educação, nível de Mestrado, Unidade Universitária de Paranaíba.

E-mail: doracina@smail.com 